Fecha de recepción: octubre 2008 Fecha de aceptación: noviembre 2008 Versión final: diciembre 2008

\section{Yendo donde están las audiencias. Internet: el nuevo aliado de las relaciones públicas}

Alberto Arébalos ${ }^{(*)}$

\footnotetext{
(*) Alberto Arebalos es Director de Comunicaciones Corporativas y Asuntos Públicos de Google, a cargo de la región de Latam con base en Buenos Aires.
}

Resumen: Este artículo analiza el impacto de la revolución on-line haciendo un paralelo con las grandes revoluciones que generan cambios profundos globales y modifican las reglas. Describe sus características, identifica elementos y actores, y reflexiona: ahora ¿los mensajes y la reputación de las organizaciones están en manos de los consumidores? En el ámbito de la Web 2.0 ¿̇los televidentes son productores, los lectores editores y un adolescente puede ser un líder de opinión? ¿Y el mix de comunicación, cómo se compone? Un nuevo mundo. Un escenario cambiante que se convierte en una nueva oportunidad para el profesional de Relaciones Públicas en su gestión, y para las organizaciones en su vinculación con sus audiencias.

Palabras claves: Relaciones Públicas - medios online - medios sociales - redes sociales - blogs - Relaciones con los Consumidores - Web 2.0 - comunicación viral - gestión comunicacional - audiencias - públicos imagen corporativa - reputación - organización - gestión comunicacional - planes de comunicación - comunicación corporativa - comunicación empresaria - comunicación institucional

[Resúmenes en inglés y portugués en la página 26]

Que Internet ha cambiado la forma de hacer negocios, aprender, trabajar, entretenerse, buscar y recibir información $-y$ hasta conseguir pareja- se ha repetido hasta el cansancio. Pero no por eso deja de ser cierto.

La revolución on-line ha tocado miles de industrias, ha transformado a todas y provocará la extinción de unas cuantas. Esa sensación de cambio profundo, de nuevas reglas (que para colmo se intuyen pero no se conocen del todo) y hasta de caos, nos inquieta y preocupa a quienes trabajamos en Relaciones Públicas, toda vez que somos conscientes de una revolución en marcha, pero de la cual aún no se logra ver bien su dirección.

Es la misma sensación que podría haber tenido un observador parado en la puerta del Palacio de Invierno hace 90 años: la revolución estaba ahí pero nadie podía saber que después vendría la URSS, la Segunda Guerra Mundial, la Cortina de Hierro, la Guerra Fría y, sin que se disparase un solo tiro, el desplome del imperio soviético.

Y la elección de ese ejemplo es porque los efectos de la revolución rusa se sintieron a escala planetaria. De hecho, desde la llegada del hombre a la luna, hasta la creación de las organizaciones mundiales fueron consecuencia imprevista de los hechos de octubre. 
La misma revolución a escala planetaria está ocurriendo ante los ojos de todos pero, por obvias razones, aún no se puede ver hacia dónde va y en qué desembocará. Sin embargo, sí se ve el cambio cada día, cuando se piensa en cómo hacer Relaciones Públicas en forma más efectiva.

¿Debería preocuparnos la revolución que se está gestando gracias a Internet? Más aún... ¿debería preocuparnos esta nueva fase de la Red, cuya principal característica es la horizontalidad, en la que cualquiera tiene la capacidad de ser un editor o un generador de opinión?

Es cierto que por años los profesionales de Relaciones Públicas hemos trabajado con ciertas tácticas, como la de usurpar la credibilidad de un tercero (un columnista, un medio reconocido) para otorgar a los mensajes la credibilidad que obviamente no puede conseguirse con la publicidad. Después de todo, la verdadera potencia de las Relaciones Públicas no está en sus menores costos sino en la capacidad de construir una respuesta determinada en un público determinado, a partir de la persuasión. Por décadas, los diarios, la radio y posteriormente, la televisión fueron los medios para alcanzar a esas audiencias -cautivas- con nuestros mensajes. Los comunicados de prensa eran el objeto más corriente en nuestra caja de herramientas, seguidos por la entrevista y alguno que otro artículo de opinión.

Pero la lista de medios y contactos era relativamente fácil de confeccionar. La sensación de que la empresa u organismo y sus comunicadores podían estar en control del mensaje era sumamente clara y el mundo tenía esa tranquilizante apariencia de ser ordenado y armónico.

Los primeros indicios de que esa armonía ya no sería lo que era fue la televisión por cable, que provocó que las audiencias empezaran a fracturarse y a verticalizarse. Pero si bien aumentaron las bocas de salida, la adaptación no fue difícil: después de todo seguía siendo televisión, muchas veces incluso con más necesidad de llenar espacios y, por ende, más proclive a recibir y emitir material enviado desde los departamentos de comunicaciones u oficinas de prensa.

La aparición de Internet fue tomada por el universo de las comunicaciones como si hubiera sido la de cualquier otro medio masivo. Muy pronto, los diarios tuvieron su edición on-line, periodistas del papel empezaron a tener sus newsletterss electrónicos y, en general, los medios tradicionales abrieron una ventanilla en Internet. ¿El modelo?, el de siempre: comunicación de arriba hacia abajo, con audiencias más fracturadas pero, al fin y al cabo, recibiendo los mensajes desde los centros de emisión. Pero la comúnmente llamada Web 2.0 (etiqueta que no termina de convencer porque genera la desconfianza de los lugares comunes, pero que aquí se usa por claridad) convirtió a ese mundo medianamente ordenado -donde al menos se podía sentir que se estaba en control- en un mundo diferente, donde el caos, en cierto sentido, es su orden lógico.

Ahora, nuestros mensajes y, lo que es peor, la reputación de las organizaciones para las que trabajamos están en manos ahora de los consumidores, de los que antiguamente eran receptores de información.

En el ámbito de la Web 2.0, los televidentes son productores, los lectores editores y un adolescente puede ser un líder de opinión. Es lógico entonces que, frente a este escenario, más de un profesional de las Relaciones Públicas sienta que conciliar el sueño ya no es tan fácil como antes. ¿Qué pasa cuándo un blogger empieza a hacer rodar rumores sobre nuestra organización? ¿Qué sucede si en una red social se esparce como reguero de pólvora que los productos de nuestra empresa están contaminados? ¿Quién es el editor de Internet?

Por suerte, nadie. Y todos.

Es cierto que esta ola de horizontalidad -que más que una ola es un nuevo océano-, donde cualquiera es un emisor de información, no va a desaparecer sino a profundizarse, y que al fin y al cabo es más 
una oportunidad que una amenaza. Los riesgos han aumentado, pero también las posibilidades de influir en las audiencias, que ya no están pasivas sino que arman su propio diario cada día.

Según un reciente estudio de la firma Piramyd Research, el 40 por ciento de los que tienen entre 18 y 29 años usa Internet para comunicarse, ya sea mediante $e$-mail, redes sociales o "chateo" on-line; mientras que un 37 por ciento utiliza la Red para buscar noticias e informarse. Y un 42 por ciento chequea en Internet antes de efectuar una compra.

Nuestras audiencias -sobre todo las futuras- están más tiempo en Internet que frente a otros medios. De hecho, el internauta latinoamericano pasa 4 horas más al mes en Internet que sus pares de otras partes del mundo. La consecuencia es, entonces, que lo que hoy se llama "on-line PR" pronto será PR -o RRPP- a secas. Dicho de otro modo, lo que hoy se llama tener una estrategia on-line no se diferenciará en el futuro próximo de la estrategia global de comunicaciones.

Entonces, ¿no hay que preocuparse por este fenómeno? Claro que no, si por preocuparse se entiende tener miedo o desconfianza. Más bien hay que abrazarlo, verlo como la gran oportunidad que es y, consecuentemente, adaptarse a las nuevas reglas y al nuevo mundo.

La preguntas entonces son: ¿¿cuánto de on-line debe tener nuestro mix de comunicaciones?, ¿¿debo enfocarme sólo en tácticas on-line y olvidarme de los medios tradicionales?, ¿qué hago con los bloggers? Cada pregunta ameritaría un capítulo de este libro, pero al menos se tratarán de señalar algunas generalidades que sirvan como puntos de discusión.

Si bien cada organización tiene sus objetivos de comunicación y sus públicos objetivos, es casi imposible asumir que pueda tener una forma efectiva de comunicarse sin un componente on-line. Hoy la gente acude a Internet para conocer más sobre una empresa o producto, investiga y compara precios antes de ir al centro comercial y, sin ninguna duda, lee opiniones de otros acerca de esa empresa y sus productos. Dicho de otro modo, ignorar el mundo on-line no es sólo riesgoso, sino suicida.

En este sentido, este universo es cada vez más importante desde el punto de vista de la reputación de una organización u empresa. Hoy en día en cientos de foros, blogs y redes sociales, diversos grupos hablan y discuten de marcas, empresas y organismos. Si su marca es importante, y de hecho lo es, jamás debería pasarse por alto el monitoreo de estas conversaciones.

Saber qué están diciendo los consumidores y qué piensan, y cómo se sienten acerca de su marca no sólo puede alertar sobre problemas que sus servicios o productos podrían sufrir en el corto o mediano plazo, sino hasta puede ser aprovechado como oportunidades de promoción.

En el pasado, focus groups y otros mecanismos eran utilizados de la misma manera. Hoy, con un poco de trabajo y la estrategia y medios adecuados, Internet puede ser un gigantesco focus group que, si se está dispuesto a escuchar, puede brindar una enorme cantidad de información espontánea acerca de nuestra organización.

Esta doble vía en la comunicación es quizás el aspecto más novedoso de la Web 2.0. Ahora no sólo se habla sino que la audiencia contesta y casi en tiempo real, un monólogo se ha transformado en diálogo, cacofónico a veces pero diálogo al fin.

En este sentido, una de las preocupaciones que a menudo surge se relaciona con el papel de los blogs y los bloggers. Muchos blogs son vías alternativas de comunicación de periodistas profesionales, muchos otros no. En todo caso, los bloggers necesitan tener acceso a la información con la misma rapidez y fluidez que requiere un medio tradicional. Para ellos hay que entender herramientas como los agregadores de noticias o RSS que les permiten a los bloggers saber qué sucede en una determinada empresa casi en tiempo real. Emplear estas herramientas para dar a conocer nuestros mensajes no sólo es imperativo sino crucial. Un párrafo final se quiere dedicar a los medios tradicionales. Es claro que no se está frente a un juego 
de suma cero. La prensa tradicional, que también tiene un componente on-line, sigue y seguirá siendo importante para el mix comunicacional.

Sólo que en un mundo donde los bloggers son fuente de periodistas y éstos de bloggers, y a su vez las redes sociales influencian lo que escribe la prensa y ésta lo que piensan los actores de esos foros, la única forma de aproximación a este universo de medios es en una forma holística. Si algo deja claro Internet es que ya no se trata de silos y que en la gran conversación a escala planetaria todos influyen en todos. La conclusión es que, como en toda revolución, los ejes del control y quienes lo ejercen ha cambiado. La idea de que una empresa o un profesional de las Relaciones Públicas puede controlar el mensaje está cambiando. La realidad indica que ahora el mensaje es una construcción social, el emisor tiene un papel crucial pero existen otros actores que ya no sólo reciben pasivamente esos mensajes sino que los transforman y re difunden a una velocidad y escala impensada antes.

El boca en boca existió siempre, pero nunca con este alcance ni velocidad. El gerente de marca, hoy, es el consumidor.

Si algo nos queda como profesionales de las Relaciones Públicas es que éste quizás sea uno de los momentos más interesantes de la profesión. El término comunicación social ha adquirido su verdadero significado y los desafíos se han multiplicado, al mismo tiempo que han otorgado una nueva importancia a toda la función de comunicaciones en una organización.

Como toda revolución, no se sabe aún en qué desembocará, pero se puede elegir ser parte de ella. Volviendo al ejemplo inicial: es mejor prepararse y correr hacia el Palacio de Invierno. La historia no suele detenerse ante quienes tratan de frenarla.

Summary: This article analyses the impact of the online revolution making a parallel with the great revolutions that generate deep worldwide changes and modify the settled rules. It describes his characteristics, it identifies elements and players, and it proposes a reflection: Nowadays, organizations messages and reputation are in the hands of consumers? In the scope of Web 2.0, it is possible that TV audience has become a producer, readers have become publishers, and a teenager could become an opinion leader? And the communication mix, how is made up? It is about a new world, a changing scenario that becomes a new opportunity for the professional of Public Relations in its management, and for the organizations in its entailment with their stakeholders.

Key words: Public relations - online media - social media - social networks - blogs- Consumers Relations - Web 2.0 - viral communication - communicational management - hearings - stakeholders- corporate image - reputation - organization - communication plans - corporate communication - institutional communication

Resumo: Este artigo analisa o impacto da revolução on-line fazendo um paralelo com as grandes revoluções que geram mudanças profundas globais e modificam as regras. Descreve suas características, identifica elementos e atores, e reflexiona: ¿agora as mensagens e a reputação das organizações estão em mãos dos consumidores? No âmbito da Web 2.0, ¿̇os televidentes são produtores, os leitores editores e um adolescente pode ser um líder de opinião? ¿E o mix de comunicação, como se compõe? Um novo mundo. Um palco mutante que converte-se numa nova oportunidade para o profissional de Relações Públicas em sua gestão, e para as organizações em sua vinculação com suas audiências.

Palavras chave: Relações Públicas - meios online - meios sociais - redes sociais - blogs - Relações com os Consumidores - Web 2.0 - comunicação viral - gestão comunicacional - audiências - públicos imagem corporativa - reputação - organização - gestão comunicacional - planos de comunicação - comunicação corporativa - comunicação empresária - comunicação institucional 